\title{
Hole expansion of dual phase steels
}

\author{
L. Xu ${ }^{1}$, F. Barlat ${ }^{1}$, M. G. Lee ${ }^{1}$, K. S. Choi ${ }^{2} \&$ X. Sun ${ }^{2}$ \\ ${ }^{I}$ Materials Mechanics Laboratory, Graduate Institute of Ferrous \\ Technology, Pohang University of Science and Technology, South Korea \\ ${ }^{2}$ Pacific Northwest National Laboratory, USA
}

\begin{abstract}
In this work, the stretch-flangeability of dual phase (DP) steels was investigated through hole expansion (HE) tests for three DP980 steel sheet samples. In order to understand the effect of hole surface quality on the HE results, the specimens were prepared with three hole machining methods, namely, electrical discharge machining (EDM), punching and laser cutting. The HE results were discussed in terms of the hole surface quality before and after testing. Moreover, the failure behaviour was analyzed based on the observations of the fracture surfaces using optical microscopy (OM) and scanning electron microscopy (SEM).

Keywords: dual phase steel, hole expansion, hole surface quality, failure.
\end{abstract}

\section{Introduction}

Advanced high strength steels (AHSS) have been continuously improved to meet the various requirements of the automotive industry, such as vehicle weight reduction, crash performance improvement, energy saving considerations and environmental protection. For example, dual phase (DP) steels have increasingly been used in various vehicle components. Typical DP steel sheets have an excellent combination of high strength and elongation, but poor stretchflangeability. The hole expansion (HE) test has been recognized as a discriminating method to characterize stretch-flangeability. Moreover, it is well known that the hole surface quality has a significant effect on the HE results. Although many papers have focused on the HE tests of DP steel sheets [1-5], only a few of them investigated the effect of hole surface quality on the HE results and failure behaviour $[6,7]$.

In this work, the stretch-flangeability for three DP980 steel sheet samples, denoted materials $\mathrm{A}, \mathrm{B}$ and $\mathrm{C}$, and provided by different steel producers, was 
investigated through the flat-bottom HE tests. Uniaxial tension tests were performed to characterize the flow behaviour and plastic anisotropy in uniaxial tension. In order to investigate the effect of the surface quality, the HE specimens were prepared with three hole machining methods, namely, electrical discharge machining (EDM), punching and laser cutting. Moreover, the fracture surfaces of the HE specimens were observed using optical microscopy (OM) and scanning electron microscopy (SEM).

\section{Experiments and results}

\subsection{Chemical composition}

Chemical composition analyses were performed for the three DP980 steels using Inductively Coupled Plasma-Atomic Emission Spectroscopy (ICO-AES) and ASTM E 1019-08 standard. The combustion-infrared absorption method was used to determine carbon and sulphur while the inert gas fusion-thermal conductivity method was used for nitrogen. For these analyses, the coating, if any, was ground off the sample surfaces. Table 1 lists the chemical composition of the three materials. Note that the thickness of the sheets is also given in the table. Generally, for the three materials, there is no significant difference in contents of the different elements.

Table 1: $\quad$ Chemical composition of the three DP980 steel sheets (in wt \%).

\begin{tabular}{|c|c|c|c|c|c|c|c|c|c|}
\hline Material & $\mathrm{C}$ & $\mathrm{Cr}$ & $\mathrm{Mn}$ & $\mathrm{Mo}$ & $\mathrm{Si}$ & $\mathrm{P}$ & $\mathrm{S}$ & $\mathrm{N}$ & Thickness \\
\hline $\mathrm{A}$ & 0.11 & 0.26 & 2.38 & 0.20 & 0.08 & 0.008 & 0.003 & 0.008 & $1.0 \mathrm{~mm}$ \\
\hline $\mathrm{B}$ & 0.10 & 0.47 & 2.09 & 0.28 & 0.18 & 0.007 & 0.002 & 0.004 & $1.4 \mathrm{~mm}$ \\
\hline $\mathrm{C}$ & 0.08 & 0.47 & 2.08 & 0.28 & 0.18 & 0.008 & 0.003 & 0.004 & $1.4 \mathrm{~mm}$ \\
\hline
\end{tabular}

\subsection{Uniaxial tension test}

Standard uniaxial tension tests were conducted to determine the flow behaviour and plastic anisotropy of the three DP980 steel sheet samples. The tests were performed using specimens prepared according to sub-size ASTM E8 standard at a strain rate of $10^{-4} / \mathrm{s}$. All specimens were cut using EDM. For each material, three specimens were deformed in the rolling direction (RD) and transverse direction (TD). The corresponding stress-strain curves are shown in fig. 1 . Extensometers were used to measure the longitudinal and transverse strains, and the $r$ values were calculated assuming volume constancy during plastic deformation as expressed in eqn (1):

$$
r=-d \varepsilon_{\beta} / d \varepsilon_{\gamma}=-d \varepsilon_{\beta} /\left(d \varepsilon_{\beta}+d \varepsilon_{\alpha}\right)
$$

Here, $\alpha, \beta, \gamma$ represents the longitudinal, transverse and normal thickness directions (ND) of the specimen, respectively. The $r$ values are listed in table 2 . 


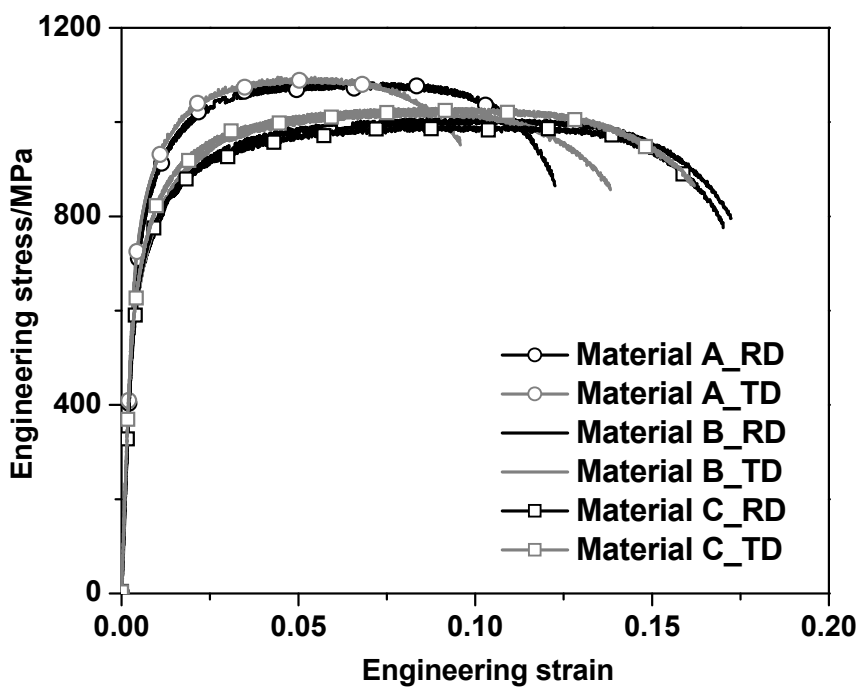

Figure 1: The engineering stress-strain curves from the uniaxial tension tests in the RD and TD for the three DP980 steels.

Table 2: The $r$ values from the uniaxial tension tests for the three DP980 steels.

\begin{tabular}{|c|c|c|c|}
\hline Material & $\mathrm{A}$ & $\mathrm{B}$ & $\mathrm{C}$ \\
\hline$r_{R D}$ & 1.00 & 0.99 & 0.96 \\
\hline$r_{T D}$ & 1.26 & 1.16 & 1.37 \\
\hline
\end{tabular}

\subsection{Hole expansion test}

In this work, an Erichsen hydraulic sheet metal tester with a $600 \mathrm{KN}$ capacity was used to perform the flat bottom HE tests for the three materials. A schematic view of the test is shown in fig. 2. During the test, a square specimen with a central hole was first clamped between the lower blank holder and the upper die. The draw-in of the outer sample periphery was prevented by means of a high constant blank holder force of $100 \mathrm{KN}$. Then, a punch force was applied with a punch velocity of $20 \mathrm{~mm} / \mathrm{min}$. Once a primary crack was visually observed, the test was manually stopped. A fractured specimen is represented in fig. 3. The initial hole diameter $d_{0}$ was $12 \mathrm{~mm}$. After the specimen fractured, the diameter of the fractured hole, $d_{f}$, was measured in two directions and averaged. The hole expansion ratio (HER) value is calculated using eqn (2):

$$
H E R=\frac{d_{f}-d_{0}}{d_{0}} \times 100 \%
$$




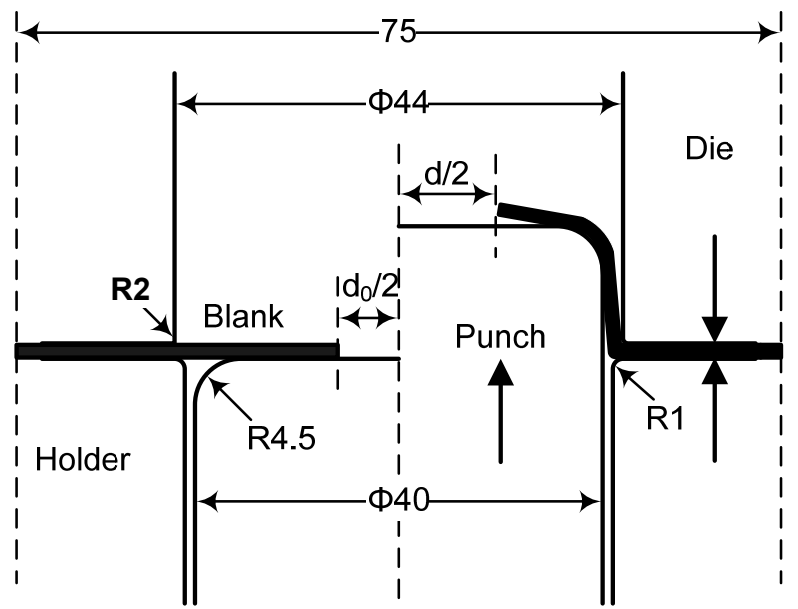

Figure 2: Experimental schematic of the hole expansion test (dimension: $\mathrm{mm}$ ).

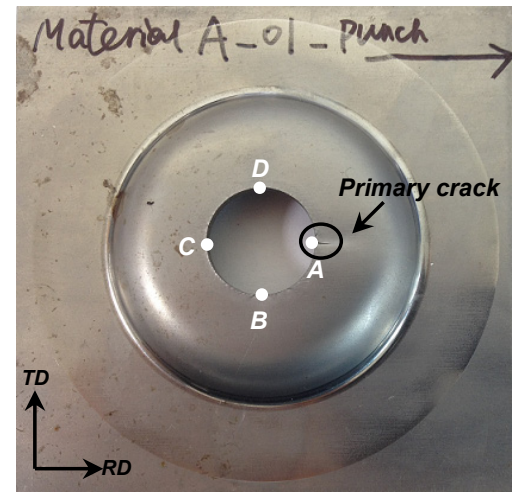

Figure 3: A fractured specimen from the hole expansion test.

As mentioned before, the performance of a material in the HE test is sensitive to the hole surface quality. In this work, EDM, punching and laser cutting were used to manufacture the central hole of the specimens. Three tests were carried out for each machining method. The average HER values are presented in fig. 4 . As shown in the figure, among the three machining methods, EDM led to the highest HER values for all materials, while punching method resulted in the lowest ones. Laser cutting produced slightly lower HER values than EDM.

In addition, the number of specimens for which the first primary crack occurred along the RD or TD is given in table 3. For all materials, most of the EDM specimens fractured along the TD. However, for the specimens with 


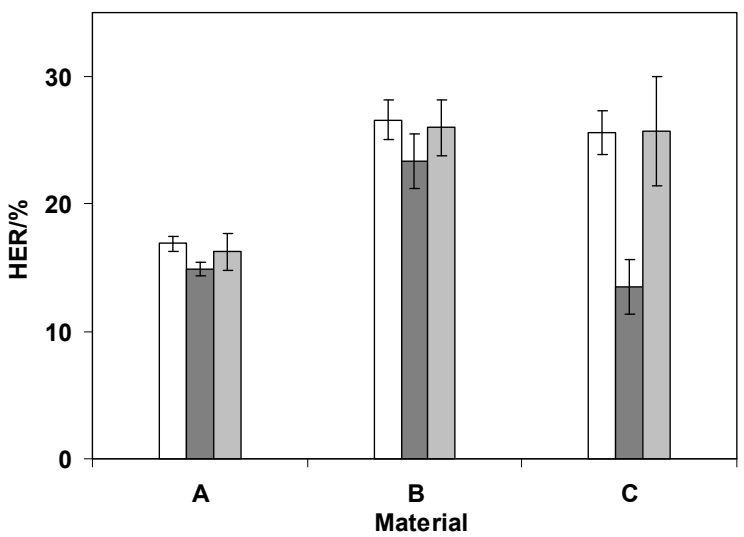

Hole maching method: $\square$ EDM $\square$ Punching $\square$ Laser cutting

Figure 4: The HER values with different machining methods for the three DP980 steels.

punching and laser cutting, it seems there is no preferential failure direction. For example, for most of the laser cut specimens, failure occurred along the TD for material $\mathrm{A}$, but it appeared along the $\mathrm{RD}$ for material $\mathrm{C}$.

Table 3: The number of the hole expansion specimens for which the first primary crack occurred along the RD or TD. The symbol * means the cracks occurred along the RD and TD simultaneously.

\begin{tabular}{|c|c|c|c|c|c|c|}
\hline \multirow{2}{*}{ Material } & \multicolumn{2}{|c|}{ EDM } & \multicolumn{2}{c|}{ Punching } & \multicolumn{2}{c|}{ Laser cutting } \\
\cline { 2 - 7 } & RD & TD & RD & TD & RD & TD \\
\hline A & 1 & 2 & 3 & 0 & 1 & 2 \\
\hline B & $1^{*}$ & $2+1^{*}$ & 1 & 2 & 1 & 2 \\
\hline C & 0 & 3 & 3 & 0 & $2+1^{*}$ & $1^{*}$ \\
\hline
\end{tabular}

\section{Discussion}

Since the three DP980 steel sheets exhibit the same tendency of HER values using different machining methods, in this section material $\mathrm{C}$ is taken as the example to simplify the explanation of the HE for DP980 steels.

\subsection{Effect of hole surface quality}

In order to clarify the effect of hole surface quality on the HE results, the hole surfaces were observed using optical microscopy (OM) before and after testing. Figs 5 and 6 respectively shows the micrographs of the hole surfaces before and after testing for material C. It is demonstrated in fig. 5 that the hole surface experienced different amounts of deformation during the hole machining 
process. Compared with EDM and laser cutting, the punching method obviously produced the most damage to the hole surface. In addition, the hole surface of the EDM specimen is the most uniform. Finally, it can be observed in fig. 5(c) that the laser cutting process produced a deeper damage at the start point of the process. This is likely to produce a larger stress concentration during the HE.

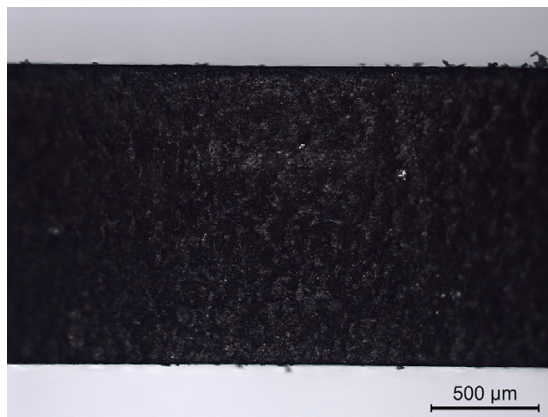

(a)

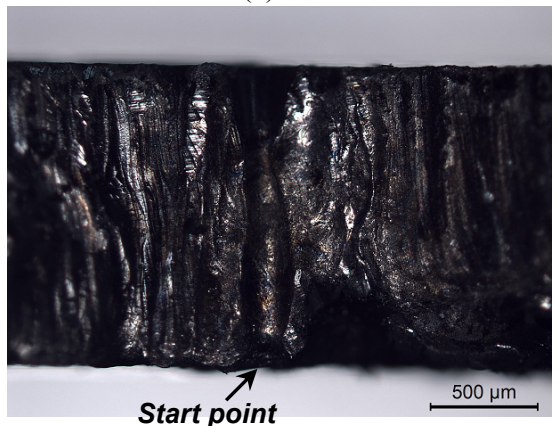

(c)

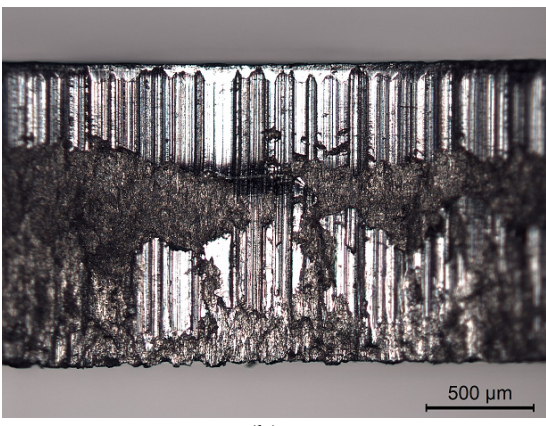

(b)

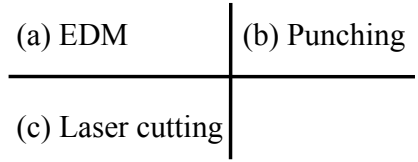

Figure 5: Micrographs of the hole surface before testing with different machining methods for material $\mathrm{C}$.

Fig. 6 shows that, for the specimen obtained with EDM, the thickness at the fracture location is the smallest, indicating that significant plastic localization occurred, compared with those of the specimens with punching and laser cutting. This means that the EDM specimen experienced the largest amount of deformation during the HE test. This is consistent with the highest HER values achieved with the EDM specimens as shown in fig. 4. Since the initial hole surface of the punched specimen was most damaged, it is not surprising that the corresponding fractured specimen exhibited the largest thickness and resulted in the lowest HER values among the three machining methods. In addition, as presented in fig. 6(b), a few cracks can be observed close to the fracture location for the punched specimen, which is another evidence for high damage level. 


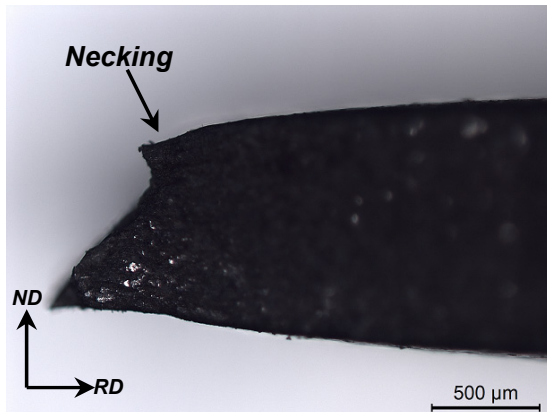

(a)

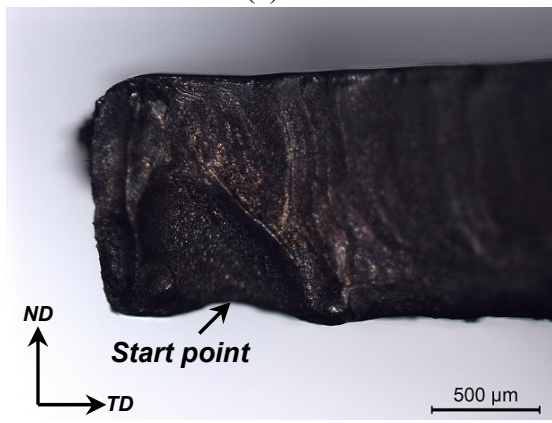

(c)

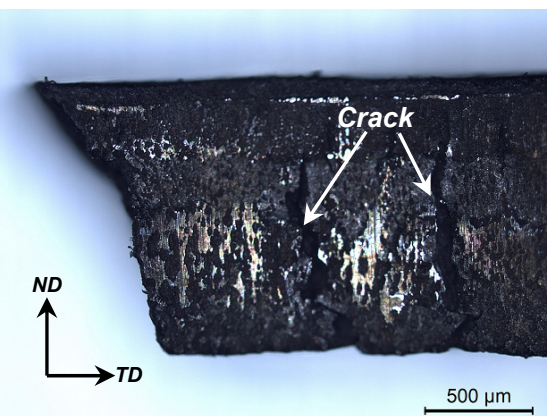

(b)

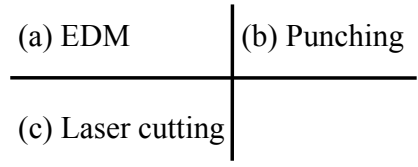

Figure 6: Micrographs of the hole surface after testing with different machining methods for material $\mathrm{C}$.

\subsection{Failure analysis}

In order to understand the failure of DP980 steel sheets during HE, the failure direction was analyzed. For the specimens with EDM, the fracture direction can be explained in terms of plastic anisotropy. In fig. 3, the points $\mathrm{A}$ and $\mathrm{C}$ on the specimen deform in TD uniaxial tension, while the points $\mathrm{B}$ and $\mathrm{D}$ deform in $\mathrm{RD}$ uniaxial tension. As indicated in table 2, the $r$ value in the TD is larger than that in the RD. Therefore, the thickness in points $\mathrm{A}$ and $\mathrm{C}$ should be larger than that in points B and D during plastic deformation. Moreover, as shown in fig. 6(a), necking localization occurred before fracture. Therefore, when the common necking theories $[8,9]$ are applied for the material, the smaller thickness at points $\mathrm{B}$ and $\mathrm{D}$ would result in the failure along the TD. This agrees with the experimental results in which most of the EDM specimens fractured along the RD. It is worth mentioning that Kuwabara et al. [1] reported that the fracture of a DP780 steel sheet sample with the hole prepared by wire-EDM also initiated at the hole location with the lowest thickness in the HE test. For the laser cut specimen, a deep indent can be observed close to the fracture location as shown in fig. 6(c). This indent corresponds to the deeper damage from the start of the laser cutting process indicated in fig. 5(c). This means that, for the specimen produced with laser cutting, the location of fracture initiation is determined by 
the start position of the laser machining. After initiation, the fracture usually propagated along the radial direction. Therefore, this suggests that improving the initial stage of laser cutting can lead to a better HER value. For the punched specimens, the first primary crack does not seem to have any preferential orientation. In addition, accompanying the first primary crack, many minor cracks evenly distributing along the hole edge can be observed.

Since most of the failures occurred along either the RD or TD as shown in table 3, the fracture surfaces in the rolling and transverse planes were observed using scanning electron microscopy (SEM). The fractographs in the rolling plane from the EDM specimen and those in the transverse plane from the laser cut specimen are shown in figs 7 and 8 respectively. It can be observed from the two figures that, the fractographs in both planes seem to be very similar and exhibit small and round dimples. Some comparatively large voids can also be found in both planes.

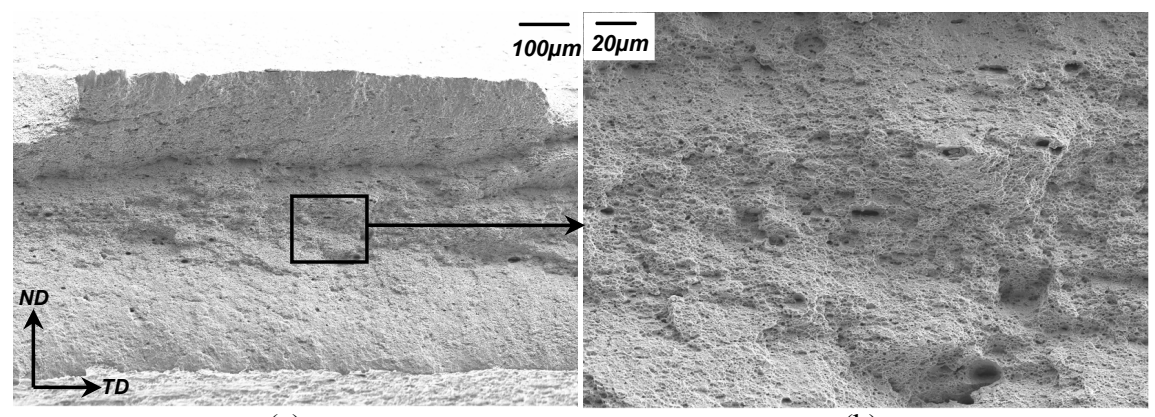

(a)

(b)

Figure 7: Fractographs in the rolling plane from the hole expansion specimen using EDM for material C.

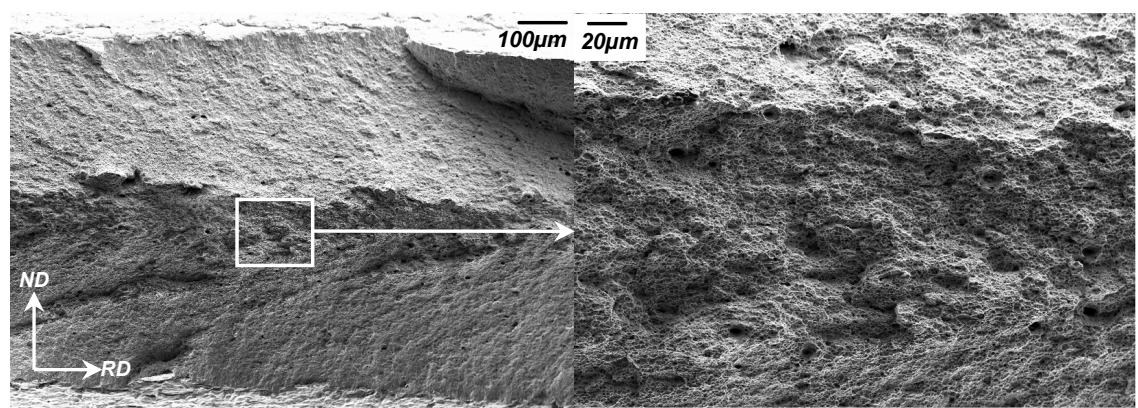

(a)

(b)

Figure 8: Fractographs in the transverse plane from the hole expansion specimen using laser cutting for material $\mathrm{C}$. 


\section{Conclusions}

In this work, hole expansion tests were performed to investigate the stretchflangeability of three DP steel sheets. Hole expansion results with three hole machining methods, namely, EDM, punching and laser cutting, were compared. Moreover, the hole surfaces before and after testing were observed using OM and SEM. The experimental results showed that, for the specimens with EDM, the HER values are the highest and necking localization appeared for the three materials. In addition, the fracture mostly occurred along the RD due to the plastic anisotropy of the material. Punching method led to the most damage to the hole surface, and thus the lowest HER values. For the specimens with laser cutting, the first primary crack initiated at the start position of the laser cutting process. It was also shown that the fractographs in the rolling and transverse planes were very similar.

\section{References}

[1] Kuwabara, T., Hashimoto, K., Iizuka, E. and Yoon, J.W., Effect of anisotropic yield functions on the accuracy of hole expansion simulations, Journal of Materials Processing Technology, 211, pp. 475-481, 2011.

[2] Lee, J., Lee, S.-J. and De Cooman, B.C., Effect of micro-alloying elements on the stretch-flangeability of dual phase steel, Materials Science and Engineering A, 536, pp. 231-238, 2012.

[3] Kim, J.H., Lee, M.G., Kim, D., Matlock, D.K. and Wagoner, R.H., Holeexpansion formability of dual-phase steels using representative volume approach with boundary-smoothing technique, Materials Science and Engineering A, 527, pp. 7353-7363, 2010.

[4] Mori, K., Abe, Y. and Suzuki, Y., Improvement of stretch flangeability of unltra high strength steel sheet by smoothing of sheared edge, Journal of Materials Processing Technology, 210, pp. 653-659, 2010.

[5] Uthaisangsuk, V., Prahl, U. and Bleck, W., Stretch-flangeability characterisation of multiphase steel using a microstructure based failure modeling, Computational Materials Science, 45, pp. 617-623, 2009.

[6] Karelova, A., Krempaszky, C., Werner, E., Tsipouridis, P., Hebesberger, T. and Pichler, A., Hole expansion of dual-phase and complex-phase AHS steels - effects of edge conditions, Steel Research International, 80, pp. 7177, 2009.

[7] Zhang, Y., Liu, Y. and Wu, X., Fracture behavior of a dual phase sheet steel in hole expansion, Processing and Engineering Applications of Novel Materials, 13, pp. 37-38, 2007.

[8] Hill, R., On discontinuous plastic states with special reference to localized necking in thin sheets, Journal of the Mechanics and Physics of Solids, 1, pp. 19-30, 1952.

[9] Marciniak, Z. and Kuczynski, K., Limit strains in the processes of stretchforming sheet metal, International Journal of Mechanical Sciences, 9, pp. 609-620, 1967. 